\title{
BENTUK TARI ZAHIFA PADA UPACARA PERKAWINAN MASYARAKAT ARAB DI KOTA MEDAN
}

\author{
SINTA WIJAYANTI \\ Prodi Pendidikan Tari
}

\begin{abstract}
This study aimed to describe Zahifa Dance Forms In Marriage Ceremony Arab Society in Medan include: (1) the function of dance, (2) form Dance Zahifa In Marriage Ceremony Arabs in the city of Medan. The theoretical foundation of this research is grounded in the theory of functions and the theory that examines forms Zahifa dance based on dance, Typewriter and accompaniment, makeup and clothing, as well as the venue floor pattern. This study used a qualitative descriptive approach. This research data is, functions and forms of dance Zahifa In Marriage Ceremony Arabs in the city of Medan. The data used is Zahifa dance at Al Fairouz community in Medan. Data were collected with a population of 11 people comprising 1 figure and 10 dancers dance Zahifa, observation, interview, and literature study. Data were analyzed using descriptive techniques. The results of this study as follows. 1) the existence of the Arab city of Medan, where the Arab community in the city of Medan is still very rare, the Arab community in the city of Medan strengthening of family by setting up a container such as community organizations. 2) The wedding ceremony Arab community in the city of Medan. 3) Function Zahifa dance on Arab communities in the city of Medan, namely as a means of ceremonies, performances and entertainment facilities. 4) The form of presentation of dance Zahifa the Arab community in the city of Medan, namely (a) motion, (b) the music or accompaniment, (c) cosmetology, (d) the pattern of the floor, (e) the venue.
\end{abstract}

Keywords: Shape dance Zahifa, Arabs in the city of Medan, Community Al Fairouz. 


\section{PENDAHULUAN}

Salah satu pulau besar di wilayah Indonesia yang penduduknya terdiri dari berbagai etnis dan sub etnis adalah pulau Sumatera. Setiap etnis memiliki ciri tersendiri, baik dari adat istiadat, kesenian maupun latar belakang membentuknya. Keragaman ciri tersebut tetap memiliki tujuan yang sama, yaitu mengembangkan kebudayaan masing-masing tanpa merubah ciri khas dari kebudayaan itu sendiri.

Kebudayaan merupakan perwujudan dari hasil pemikiran manusia yang di aplikasikan kedalam kehidupan sehari-hari dalam bermasyarakat.Begitu banyaknya suku budaya yang tersebar diseluruh nusantara memiliki warisan kebudayaan yang berbeda-beda, hal itu mencerminkan karakter atau ciri khas dari masing-masing manusia yang ada pada tiap suku budaya.Dalam kebudayaan mencakup begitu banyak aspekaspek kehidupan baik dari segi nilainilai dalam kehidupan, hokum adat, organisasi sosial dan
kesenian.Keberagaman keindahan, serta multikultur masyarakat Indonesia yang kian berkembang, menjadikan masyarakat mengenal berbagai macam budaya dari luar Indonesia, dan salah satunya adalah tari Zahifa yang berasal dari Arab. Keragaman ciri terserbut tetap memiliki tujuan yang sama, yaitu mengembangkan kebudayaan masing-masing tanpa merubah ciri khas dari budaya itu sendiri.

Etnis Arab di kota Medan adalah penduduk Indonesia yang memiliki keturunan Arab.Tradisi yang sudah menjadi bagian dari kebudayaan, adat istiadat dan kesenian daerah ini di antaranya adalah Tari Zahifa.Keberadaan tari Zahifa di Medan masih sangat jarang ditemui diberbagai daerah, hanya dikota-kota tertentu saja dan itu pun karena adanya komunitas-komunitas tari Arab.Salah satu Komunitas tari Arab yang ada di kota Medan yaitu Komunitas Al Fairouz yang dipelopori oleh Yasir Arafat.Keberadaan komunitas ini belum begitu popular ditelinga 
masyarakat Medan (wawancara Rabu 29 Juni 2016).

Al Fairouz merupakan sebuah komunitas tari di daerah Sumatera Utara tepatnya di kota Medan. Keberadaan komunitas ini sudah ada pada tahun 2011 dan memiliki 11 orang penari laki-laki.Awal terbentuknya komunitas ini karena sangat jarang orang mengetahui tentang tarian Arab. Berawal dari sinilah muncul ide sang pelopor tari untuk mengembangkan ide kreatif nya dalam bentuk tari Zahifa.

Tari Zahifa adalah sebuah tarian khas Arab yang mewujudkan ekpresi kegembiraan atas perkawinan yang dilangsungkan.Tarian ini kebanyakan dan biasanya dilakukan oleh kaum pria.Dalam setiap gerakannya para penari biasanya cukup ekspresif dan menghibur, sehingga para orang yang terlibat larut dalam kegembiraan.Bernyanyi, berteriak dan saling bercanda gurau adalah salah satu yang menari dalam tarian ini.Dalam tari Zahifa terkandung makna dimana niatan dan usaha dari pengantin pria untuk mempersembahkan sesuatu kepada istrinya. Dalam setiap gerakannya yang kompak mengandung makna dimana eratnya kekerabatan dan pertemanan satu sama lain.

$$
\text { Tari Zahifa dilaksanakan }
$$

hanya ketika ada acara-acara tertentu, yaitu pada waktu acara perkawinan saja.Tari Zahifa dilaksanakan pada malam hari sebelum acara resepsi pernikahan. Dalam proses pelaksanaannya, semua orang yang ikut terlibat dalam tari ini menggunakan busana muslim yang biasanya berwarna putih. Orang-orang yang terlibat dalam tari Zahifa adalah kaum pria dengan gerakan yang kompak.Dalam setiap gerakannya, para penari biasanya cukup ekspresif dan menghibur.Tarian ini biasanya diiringi dengan alat music gambus dan rebana. Tari Zahifa biasa dilaksanakan mulai dari jam 08.00 malam sampai dini hari sekitar jam 01.00.Untuk menjadi seorang penari Zahifa tidak mudah.Syarat yang paling utama dalam tarian Zahifa adalah harus beragama Islam dan mampu bershalawat.

Penelitian ini difokuskan tari Zahifa pada komunitas $A l$ Fairouz yang ada di Jalan Brigjend Katamso 
Gang Adil Kelurahan Sungai Mati.

Keberhasilan suatu penelitian dapat dilihat dari tercapai atau tidaknya tujuan penelitian yang telah ditetapkan. Sehingga penulis memiliki beberapa tujuan dalam penelitian yang akan diperjelas pada pembahasannya. Adapun tujuan dalam penelitian ini adalah sebagai berikut :

1. Mendeskripsikan fungsi Tari Zahifa pada upacara perkawinanmasyarakat Arab di kota medan?

2. Mendeskripsikan bentuk Tari Zahifa pada upacara perkawinan masyarakat Arab di kota Medan?

Setiap penelitian yang dilakukan diharapkan akan memberi sumbangan yang bermanfaat bagi siapa saja. Dalam kamus besar Bahasa Indonesia manfaat adalah guna atau faedah. Penelitian juga harus memiliki hasil yang berguna, terutama bagi pengembangan ilmu, baik bagi diri peneliti, maupun lembaga, instansi tertentu, ataupun orang lain yang membacanya. Dan apabila penelitian yang dilakukan tidak ada manfaatnya maka hasil penelitian itu gagal tentunya, untuk itu berdasarkan kajian yang akan diteliti nantinya, maka dapat diambil beberapa manfaat yang bisa menjadi pedoman dan informasi bagi pembaca, antara lain :

1. Sebagai masukan bagi penulis dalam menambah pengetahuan dan wawasan mengenai Tari Zahifa.

2. Sebagai motivasi agar lebih membangkitkan rasa cinta akan tradisi dan adat istiadat yang dimiliki serta turut andil dalam menjaga dan melestarikannya.

\section{Landasan Teoritis}

Landasan teoritis yang dimaksud adalah sebagai pedoman berfikir dalam melaksanakan penelitian atau sebagai landasan dalam melaksanakan penelitian yang merupakan suatu uraian teori dan suatu masalah yang akan dibahas. Maka jelaslah bahwa permasalahan di dalam penelitian ini sangat erat hubungannya dengan buku yang dijadikan acuan untuk mengetahui eksistensi kelompok tari Zahifa pada masayarakat Medan. 


\section{Tempat dan Waktu Penelitian}

Tempat penelitian sesuai dengan judul yang diajukan untuk proposal penelitian ini adalah di Jalan Brigjend Katamso Gang Adil Kelurahan Sungai Mati No.59 Kode Pos 20159 Kota Medan.

Rentang waktu yang diperlukan peneliti adalah minimal tiga bulan, mulai dari bulan Juni 2016 hingga Agustus 2016.

\section{Populasi dan sampel}

\section{Populasi}

Dengan penjelasan tersebut maka yang akan menjadi populasi dalam penelitian ini adalah Komunitas Al Fairouz.

\section{Sampel}

Mengingat bahwa jumlah seniman tari Zahifa sangat terbatas, maka yang menjadi sampel dalam penelitian ini adalah keseluruhan dari populasi yang berjumlah 11 orang yang terdiri dari 1 orang tokoh tari Zahifa daerah setempat dan 10 orang penari tari Zahifa dalam Komunitas Al Fairouzdi Jalan Brigjend Katamso Kota Medan, sehingga penelitian ini disebut dengan penelitian populasi.

\section{Teknik Pengumpulan Data}

Dalam penulisan ini, teknik pengumpulan data yang digunakan meliputi:

1. Observasi

2. Studi Kepustakaan

3. Wawancara

4. Dokumentasi

\section{Teknik Analisis Data}

Semua data yang diperoleh dari tempat penlitian dicatat, kemudian diolah dan dianalisis dengan diteliti. Hasil olahan data dan analisis tersebut akan dijadikan sebagai bahan tulisan yang nantinya dapat ditemukan tema yang akan dirumuskan. Selanjutnya hasil pengolahan data analisis tersebut disusun secara sistematis dengan teknik deskriptif kualitatif, sehingga hasilnya dapat dilihat dalam suatu bentuk laporan karya ilmiah atau skripsi yang dalam penelitian ini dicapai dengan jalan : membandingkan data hasil pengamatan dengan data hasil wawancara dengan isi suatu dokumen yang berkaitan. Penyajian data yang terkumpul diarahkan untuk menjelaskan Bentuk Tari Zahifa 
Pada Upacara Perkawinan

Masyarakat Arab Di Kota Medan.

\section{HASIL PENELITIAN}

Pernikahan orang Arab di kota Medan secara syariat tentu sama dengan masyarakat muslim pada umumnya, yakni diawali dengan pertunangan. Khusus di lingkungan atau keturunan masyarakat Arab, pertunangan erat hubungannya dengan kesanggupan menyerahkan sejumlah uang kepada pihak mempelai calon pengantin wanita.Berfariasi tentang jumlah uang yang diminta oleh keluarga calon pengantin wanita, bergantung dengan tingkat status sosial dari kedua calon pengantin.Semakin tinggi tingkat status sosial kedua calon pengantin semakin tinggi pula tingkat permintaan dan kesanggupan calon pengantin laki-laki.Setelah terjadi kesepakatan, maka dilakukanlah rangkaian pernikahan yang diawali dengan acara ijabqobul yang dilanjutkan pada acara resepsi pesta perkawinan. Pada acara Ijab Qobul ini dilakukan di depan mutawaif yang dihadiri oleh kedua belah pihak pasangan pengantin, beserta beberapa karib kerabat kedua belah pihak.

Hal lain yang sangat penting dalam pernikahan masyarakat keturunan arab di kota Medan adalah adanya perjanjian pernikahan yang ditandatangani oleh kedua belah pihak yang juga ditandatangani oleh para saksi yang menguraikan tentang tanggungjawab secara spesifik tentang hal-hal yang berhubungan dengan perkawinan, tentang jumlah uang yang diserahkan kepada wali, tentang mas kawin dan hal-hal lain yang menyangkut tentang hak dan kewajiban setelah perkawinan dilangsungkan.

Acara pesta diisi dengan berbagai hiburan berupa menyanyi joget dan berdansa, di sajikan dengan beragam makanan dan minuman. Acara pesta ini biasanya berlangsung hingga menjelang subuh.Memang hiburan menyanyi dan berjoget hanya mendengarkan lewat alat musik yang disediakan, bukan pertunjukan musik seperti life, kecuali musik yang ada hanya berupa musik sederhana seperti rebana dan musik klasik. 


\section{Bentuk Tari Zahifadi Kota Medan}

Dalam pelaksanaannya, tari Zahifa dilaksanakan hanya ketika ada acara-acara tertentu. Di kampung arab tempat penulis melakukan observasi, tari Zahifa dilaksanakan pada waktu ada acara pernikahan. Tari Zahifa dilaksanakan pada malam hari sebelum acara resepsi pernikahan yang pada esok harinya akan dilaksanakan. Pertunjukan tari Zahifa ini diadakan oleh kerabat dan keluarga pengantin pria yang diadakan di rumah pengantin wanita.

Tari dan musik mempunyai kesamaan fungsi yaitu sebagai medi komunikasi. Proses terbentuknya sebuah komposisi tari dapat disejajarkan dengan proses terbentuknya komposisi dalam gerakan. Dalam komposisi tari biasanya sebuah gerakan terdiri atas beberapa makna yang mengandung arti dalam sebuah tarian. Tari Zahifa memiliki unsur-unsur bentuk penyajian yang terdiri dari gerak, iringan, tata rias dan busana, pola lantai, tempat pertunjukan, yang akan diuraikan sebagai berikut:

\section{Bentuk Gerak Tari Zahifa}

1. Mbustqa (salam pembuka)

Berdiri tegak dengan posisi tangan kanan dan kiri disamping, posisi kaki berjalan maju mundur dan pandangan kedepan.

\section{Nauf}

Posisi tangan bergenggaman dengan pasangan sambil berputar serta rentak kaki harus kompak sambil berputar, pandangan kebawah.

\section{Nyentang}

Gerak rentak kaki dimana posisi kaki kiri di angkat dan kaki kanan sebagai tumpuan, posisi tangan kiri diangkat sejajar dengan bahu dan tangan berada tepat disamping serta pandangan lurus kedepan.

4. Sikap Cinta Kasih

Posisi kaki kanan menapak dan kaki kiri diangkat, posisi tangan kanan menyentuh lantai dan kaki kiri berada disamping, pandangan mengarah kebawah.

5. Sikap Sema

Melakukan gerakan kedepan dan kebelakang secara berpasangan dengan posisi tangan bergandengan dengan pasangan dan saat bergerak 
posisi badan tegak dan sedikit mendada.

\section{Alat Musik Instrumen atau}

\section{Iringan}

Dalam mengiringi tari Zahifa biasanya menggunakan rebana, gambus, akordeon terkadang juga menggunakan keyboard dan audio mp3. Alat musik yang digunakan dalam tarian Zahifa adalah gambus, akordeon, rebana.

\section{Tata Rias dan Busana}

Pada tari Zahifa, para penari tidak menggunakan riasan seperti halnya tari-tari lain (natural). Para penari Zahifa hanya menggunakan busana atau kostum tertutup.

1. Songkok (Lobe)

2. Baju Koko

3. Sarung

Berdasarkan kostum yang digunakan dalam tari Zahifa di atas, terkadang banyak juga orang yang menarikan tari Zahifa ini menggunakan pakaian bebas tetapi sopan serta menutup aurat bagi kaum laki-laki.

\section{Pola Lantai}

Pola lantai tari Zahifa yaitu hanya sejajar yang memiliki makna simbolik agar kedua mempelai saling berdampingan dan bersama-sama disetiap kegiatan yang akan diikuti oleh suami ataupun sang istri.

\section{Tempat Pertunjukan}

Tempat pertunjukkan tari Zahifa tidak ada aturan khusus harus berbentuk proscenium, arena, pendhapa dan sebagainya, karena semua tergantung pada acara pementasannya. Pada komunitas tari Zahifa biasanya lebih sering ditarikan didalam rumah atau dihalaman rumah.Dilihat dari sejarah dan fungsi untuk tari Zahifa di Arab lebih sering menggunakan panggung arena dan outdoor karena tarian ini memiliki pola lantai dasar sejajar.

\section{Kesimpulan}

Berdasarkan penelitian terhadap Bentuk Tari Zahifa pada upacara perkawinan Masyarakat Arab di Kota Medan kesimpulan sebagai berikut.

a. Upacara Pernikahan Masyarakat Arab di Medan 
Pernikahan orang Arab di kota Medan secara syariat tentu sama dengan masyarakat muslim pada umumnya, yakni diawali dengan pertunangan. Khusus di lingkungan atau keturunan masyarakat Arab, pertunangan erat hubungannya dengan kesanggupan menyerahkan sejumlah uang kepada pihak mempelai calon penganten wanita.Berfariasi tentang jumlah uang yang diminta oleh keluarga calon pengantin wanita, bergantung dengan tingkat status sosial dari kedua calon pengantin.

b. Sejarah Tari Zahifa Pada Komunitas Al Fairouz

Terbentuknya komunitas tari Zahifa Al Fairouz di Kota Medan berawal ketika Yasir Arafat (narasumber) mengahdiri acara perkawinan orang arab di Jakarta, dimana ada beberapa penari Zahifa menari dengan kompak dan menghibur tamu di malam sebelum acara pernikahan berlangsung esok harinya. Pada saat itu, Yasir Arafat hanya bisa terpana kagum, serta bertanya dalam hati bagaimana teknik dalam menarikan tarian Zahifa ini. Terbayang olehnya saat itu untuk bisa menarikan tari Zahifa dan mampu menarikannya.Hal inilah yang menjadikan motivasi Yasir Arafat untuk bisa menari Zahifa dan membuat komunitas yang mampu menarikan tari Zahifa.Karena tidakadanya kelompok seniman tari Zahifa di Kota Medan, Yasir Arafat memanfaatkan peluang ini untuk mengembangkan tari Zahifa khsusunya di Kota Medan.

c. Fungsi tari Zahifa pada komunitas Al Fairouz, yaitu:

1. Sebagai Sarana Upacara

Upacara merupakan satu tindakan yang dilakukan menurut adat kebiasaan atau keagamaan yang menandai kesakralan atau kehikmatan suatu peristiwa. Tari upacara memiliki peranan penting dalam kegiatan adat, khususnya kegiatan yang berkaitan dengan kelahiran, kedewasaan dan kematian.Tari juga digunakan untuk mempengaruhi alam 
lingkungan, hal ini menyangkut system kepercayaan masyarakat. Upacara berkaitan dengan system kepercayaan ini erat kaitannya dengan kehidupan manusia.Dalam upacara umumnya memiliki makna dan tujuan untuk menghormati, mensyukuri, memuja dan memohon keselamatan pada Tuhan Yang Maha Esa.Upacara tradisional mengandung aturanaturan yang wajib dipatuhi oleh setiap masyarakat pendukungnya.

2. Sebagai Sarana Pertunjukan

Tari pertunjukan adalah bentuk komunikasi sehingga ada penyampaian pesan dan penerima pesan. Tari ini lebih mementingkan bentuk estetika dari pada tujuannya.Tarian ini lebih digarap sesuai dengan kebutuhan masyarakat setempat, tarian ini sengaja disusun untuk dipertontonkan.Oleh sebab itu, penyajian tari mengutamakan segi artistiknya yang konsepsional, kereografer yang baik serta tema dan tujuan yang jelas.

\section{Sebagai Sarana Hiburan}

Tari sebagai media hiburan harus bervariasi sehingga tidak menjemukan dan menjenuhkan.Oleh karena itu, jenis ini menggunakan tematema yang sederhana, tidak muluk-muluk, diringi musik yang enak dan mengasyikan. Kostum dan tata panggungnya dipersiapkan dengan cara menarik. Tari memiliki tujuan hiburan pribadi lebih mementingkan kenikmatan dalam menarikan.Tari Zahifa merupakan gerak tari yang hanya bergerak bebas tetapi kompak dalam menarikannya, mengenakan pakaian sopan (menutup aurat) dan menggunakan tutup kepala.Tari Zahifa ternyata dipelajari oleh komunitas tari Zahifa Al Fairouz dan sering diminta pentas dalam berbagai acara.Dalam penyajian tari Zahifa yang ditarikan oleh komunitas tari Zahifa Al Fairouz terkait berbagai kepentingan salah satunya terkait dengan kepentingan hiburan, sehingga kostum yang digunakan pun 
tidak harus menggunakan pakaian-pakaian tertentu. Hiburan yang dimaksud adalah komunitas Al Fairouz menggunakan tari Zahifa ini untuk menghibur para penikmat tari yang berupa pentas-pentas diacara hari besar agama Islam, acara pernikahan, dan sebagainya..

d. Bentuk tari Zahifa pada komunitas tari Sufi $A l$

Fairouz.

Bentuk yang dimaksudkan dalam seni adalah sebagai rupa indah yang menimbulkan kenikmatan artistik melalui serapan penglihatan atau pendengaran.

1) Gerak pada tari Zahifa memiliki satu ragam gerak dan lima sikap dasar gerak tari.

2) Musik atau Iringan yang digunakan tari Zahifa pada komunitas Al Fairouz adalah berupa menggunakan rebana, gambus, akordeon, keyboard bahkan audio mp3 (nuansa
Islami), selain itu biasanya juga menggunakan lagu-lagu islam.

3) Tata rias tari Zahifa pada komunitas Al Fairouz tidak menggunakan riasan seperti halnya tari-tari lain.

4) Busana yang dipakai komunitas tari Zahifa $\mathrm{Al}$ Fairouz secara garis besar sama dengan tari Zahifa yang ada di Arab, hanya saja komunitas tari Zahifa $A l$ Fairouztidak menggunakan seperti di Arab, kostum yang digunakan komunitas tari ZahifaAl Fairouzialah pakaian seadanya, tidak ada ketentuan khusus dalam menggunakan pakaian ketika akan menari Zahifa, hanya saja menutup aurat dan biasanya menggunakan tutup kepala, terkadang juga menggunakan sarung sebagai pengganti celana.

5) Pola lantai tari Zahifa komunitas Al Fairouz berjajar rapi dengan menggunakan 
pola lantai sejajar.

6) Tempat pertunjukkan tari Zahifa pada komunitas $A l$ Fairouz tidak ada aturan khusus harus berbentuk arena, pendhapa, proscenium, dan sebagainya karena semua bergantung pada acara pementasannya.

\section{Saran}

Berdasarkan hasil penelitian dan pembahasan dapat disampaikan saran- saran sebagai berikut.

1. Bagi masyarakat, khususnya masyarakat di Kota Medan, hendaknya belajar tentang tari Zahifa dan mau bergabung dengan komunitas Al Fairouz agar nantinya ada kegiatan positif yang berkaitan dengan agama dan pelestarian seni.

2. Bagi pemerintah, khususnya pemerintah Kota Medan melalui Dinas Kebudayaan dan Pariwisata hendaknya lebih memperhatikan keberadaan komunitas tari ZahifaAl Fairouz, karena komunitas tari Zahifa $\mathrm{Al}$
Fairouz dalam setiappementasan tetap membawa namaKota Medan walaupun tarian tersebut berasal dari Arab.

3. Bagi komunitas tari Zahifa $A l$ Fairouz untuk lebih meningkatkan pengetahuan tentang tari Sufi, agar nantinya dapat mengetahui lebih jauh tentang pesan dan sasaran yang disampaikan melalui tarian tersebut. 


\section{DAFTAR PUSTAKA}

Abidin, 2007.Ekonomi

Pembangunan. Jakarta: PT.

Raja Grafindo Persada.

Ali Cholid Naburko, 2001. Metode

Penelitian, Jakarta: Bumi

Aksara

Ara, L.K.2009. Ensiklopedia Aceh,

Musik, Tari, Teater, Seni

Rupa. Medan:Jurnal Fakultas

Bahasa dan Seni Universitas

Negeri Medan.

Arikunto, Suharsimi. 2003. Prosedur

Penelitian. Jakarta: Rieneke

Cipta.2006. Prosedur

Penelitian. Jakarta: Rieneke

Cipta.

Arifin Nasution, Zainal. 2015.

Bentuk Lagu dan Penyajian

Qasidah MakkawiPada Ritual

Berinai Adat Melayu di

Dusun VIII Rambungan I

BandarKlippa Kabupaten

Deli Serdang. Medan: Skripsi

Fakultas Bahasa dan

SeniUniversitas Negeri

Medan.

Bungin, Burhan. 2007. Penelitian

Kualitif. Jakarta: Kencana

Pranada Media.

Chittick, C. William. 2000. Jalan

Cinta Sang Sufi:Ajaran-

ajaran SpiritualJalaluddin

Rumi. Yogyakarta: Kalam

Djelantik, A.A.M. 1999. Estetika.

Bandung

Fachdial, 2008. Fungsi Lagu Melayu

Pada Pernikahan Etnis

Melayu. Medan:Skripsi
Fakultas Bahasa dan Seni

Universitas Negeri Medan

Harmawan, Kertajaya. 2005.

Dramaturgi. Bandung: CV.

Rosdakarya

Hidayat Alimut, Aziz. 2007. Metode

Penelitian dan Teknik

Analisa Data.Surabaya:

Salemba Media.

Jazuli, M. 1994. Telaah Teoritis Seni

Tari. Semarang: IKIP

Semarang

Koentjaraningrat. 1994. Metode

Penelitian. Jakarta: Sinar

Harapan

Laili, Hazwani. 2011. Estetika

Senandung Babussalam

Masyarakat Melayu.Jurnal.

Medan: Universitas Sumatera

Utara.

Maryaeni. 2005. Metode Penelitian

Kebudayaan. Jakarta: Bumi

Aksara.

Mulyana. 2003. Komunikasi Antar

Budaya. Bandung: PT.

Remaja Rosdakarya

Mieka H, Achmad. 2013. Senandung

Dalam Tradisi Mengayunkan

Anak PadaMasyarakat

Melayu di Kabupaten

Batubara (Studi Terhadap

Bentuk MusikDan Fungsi).

Medan: Skripsi Fakultas

Bahasa dan Seni Universitas

Negeri Medan.

Najmar. 2010. Finding Rumi. Depok:

Edelweiss 
Soedarsono. 1978. Diktat Pengetahuan

dan Komposisi Tari.

Yogyakarta: ASTI

Sugiyono. 2008. Metodologi Penelitian

Kualitatif. Bandung: Remaja

Rosda Karya

Yanti, Misni. 2006. Tari Guel Pada

Upacara Perkawinan

Masyarakat BebesenAceh

Tengah. Medan: Skripsi

Fakultas Bahasa dan Seni

UniversitasNegeri Medan. 